\title{
Editorial
}

\section{Chikungunya: Bangladesh perspective}

\author{
MT Alam
}

Chikungunya fever is a mosquito borne viral illness which is transmitted by the Aedes mosquitoes. It was first isolated in 1952 at the Makonde plateau in the southern Tanzania after an epidemic. The name chikungunya derives from a word in the Kimakonde language meaning "that which bends up" and describes with stooped appearance of sufferer with joint pain ${ }^{1}$.

Chikungunya virus belongs to the family Togaviridae wth genus Alphavirus and species chikungunya virus $(\mathrm{CHIKV})^{2}$. It is a single stranded RNA virus, heat labile and sensitive to temperature above $58^{\circ} \mathrm{C}^{3}$. CHIKV is transmitted to human through the bite of an infected mosquito by Aedesaegypti which usually bite during daylight hours ${ }^{4}$.

Chikungunya is characterized by abrupt onset of fever $\left(>39^{\circ} \mathrm{C}\right)$ with joint pain. Other features are muscle pain, headache, nausea, fatigue and rash (maculopapular). But with no features of severe bleeding, hypotension/ shock or thrombocytopenia. Joint pain is often debilitating but usually last for a few days or may be prolong to weeks. Hence the virus can cause acute, sub acute or chronic disease. Pain on movement which worsen on morning, improves by mild exercise and exacerbates by strenuous exercise. Swelling is not usually accompanied by fluid accumulation. Tendinitis and fasciitis may also be clinically evident. Persistent joint pain may be mistaken for Rheumatoid Arthritis. Rash sometimes is accompanied by severe itching. Trunks and limbs are commonly involved but palms and soles also show lesions. Other clinical features like meningoencephalitis, encephalitis, photophobia and retro-orbital pain may occur ${ }^{4}$.

Death is rare but if the disease is associated with other co-morbid condition or co-infection manifestation may be severe with adverse outcome. Specific investigation for diagnosing chikungunya is viral isolation, RT-PCR, and serological diagnosis by detection of $\operatorname{IgM}$ in ELISA method. Treatment is symptomatic and no vaccine is available to prevent the disease ${ }^{5}$.

Outbreak of CHIK virus infection occurred first in 2008 at Pobaupazila in Rajshahi, Bangladesh and 39 peoples were affected. Then in 2011, 196 peoples were affected at Dohar, Dhaka ${ }^{6,7}$. Sporadic cases in 2013, 2014, 2015 with a big outbreak occured in December, 2016. From the onset of outbreak in April 1' 2017 to September 7' 2017 Ministry of Health, Bangladesh

Dr. Md. Towhid Alam, MBBS, FCPS (Medicine), Associate Professor and Head, Department of Medicine, Faridpur Medical College.

\section{Address of correspondence :}

Dr. Md. Towhid Alam, MBBS, FCPS (Medicine), Associate Professor and Head, Department of Medicine, Faridpur Medical College. Phone: +88-01712130256, E-mail: alamtowhid48@yahoo.com reported 984 cases confirmed by RT-PCR and more than 13, 176 clinically confirmed cases in 17 of 64 districts. Major outbreak has been observed in Dhaka which is home to more than 18 million people ${ }^{8}$.

A large number of media reports, editorials, TV talks as well as consciousness campaign through Facebook, Twitter and Youtube happened. Government quickly responded by arranging creation of public and professional awareness, vector control measures and management of patients. Bangladesh Institute of Epidemiology Disease Control and Research (IEDCR) with their limited resource tried it's best to control the outbreak in one of the largest megacities in the world. It is necessary to conduct detailed investigation of the outbreak with documentation of cases. IEDCR and Directorate General of Health Service (DGHS), Government of Bangladesh did an excellent job in case and vector investigation, detected Aalbopictus in all rural outbreaks and in Dhaka $A$ aegypti as predominant vector with few $A$ albopictus ${ }^{9}$.

Vector control is thus very important in controlling or preventing chikungunya transmission. Elimination of breeding site and also legislation, strong public advocacy and community involvement can also help in vector control. At last one thing is strongly we feel and that is the necessity of improving public health capacity of Bangladesh for the control of vector borne diseases ${ }^{3}$.

\section{References :}

1. Robinson MC. An epidemic of virus disease in Southern Province, Tanganyia Territory, in 1952-53. Trans R Soc Trop Med Hyg. 1955; 49: 28-32.

2. Chowdhury F, Kabir A,Das A.Chikungunya fever;an emerging threat to Bangladesh.JOM. 2012;13(1):60-64.

3. World Health Organization(WHO). Guidelines on clinical management of Chikungunya Fever. 2008;1-26.

4. World Health Organization(WHO). Chikungunia. 2017; Available from: http://www.who.int/mediacentre/factsheets

5. Bangladesh Society of Medicine. Guideline for clinical management of Chikungunya. May2017( I $^{\text {st }}$ edition $) ; 1-36$

6. ICDDR,B. First identified outbreak of Chikungunya in Bangladesh 2008, 2009. International centre for Diarrhoeal Disease Research Bangladesh. Health Sci Bull;7:1

7. Khatun S, Chakraborty A, Rahman M. An Outbreak of Chikungunya in Rural Bangladesh, 2011. PLoSNeglTrop Dis. 2015: 9 (7): e0003907. doi:10.1371/journal.pntd.0003907.

8. Hassan R, Rahman MM, Moniruzzaman M. Chikungunya- an emerging infection in Bangladesh: a case series. Journal of Medical Case Reports. 2014; 8: 1-3.

9. World Health Organization (WHO). Global vector control response 2017-2030. Geneva (version 5.4). Available from http: appa.who.int/iris/bitstrem. 